\title{
The Role of Enrollment Choice in Online Education: Course Selection Rationale and Course Difficulty as Factors Affecting Retention
}

\author{
Claire Wladis \\ Katherine Wladis \\ Alyse C. Hachey \\ Borough of Manhattan Community College \\ at the City University of New York
}

\begin{abstract}
There is well-documented evidence that online retention rates are lower than face-to-face retention rates. However, most past research on online retention focuses on student characteristics, with little knowledge existing on the impact of course type. This study uses a matched sample of 2,330 students at a large urban community college to analyze two key course-level factors which may be impacting online retention: the student's reason for taking the course (as an elective or a requirement) and course difficulty level. The results of this study indicate that the online modality increases dropout risk in courses that are taken as an elective or distributional requirement, particularly for lower-level courses. The findings suggest that in the online environment, the student's reason for course enrollment may be considered a risk indicator and that focused learner support targeted at particular course types may be needed to increase online persistence and retention.
\end{abstract}

\section{Introduction}

There has been a dramatic shift in higher education in the last decade toward online education. As a result, online courses are now a core feature of most community colleges and universities (Larreadmendy-Joerns \& Leinhardt, 2006; Layne, Boston \& Ice, 2013; Sutton \& Nora, 2008). Today, more than $30 \%$ of all college students, and more than $60 \%$ of community colleges students, enroll in online courses. Online enrollments grew by one million students from 2009 to 2010, the largest ever year-to-year increase, far surpassing the growth of higher education in general, and have increased more than 29\% since 2010 (Allen \& Seaman, 2010; Community College Research Center, 2013; Pearson Foundation, 2011). With higher education enrollments exploding today, and more technologically savvy students seeking alternate pathways to higher education, online education is expected to keep growing in the years to come (Allen \& Seaman, 2013).

Concurrent with the accelerated growth in online education is escalating concerns about student outcomes (Boston \& Ice, 2011; Hachey, Wladis \& Conway, 2013; Howell, Williams \& Lindsay, 2003). Course completion serves as an important measure of both student outcomes and the success of an online program (Abel, 2005; Moody, 2004; Willging \& Johnson, 2004). Student retention is a costly issue for institutions as well as their students. From the institutional perspective, student dropout incurs staff costs 
to handle transitions, involves extra administrative and advising time, and results in lost revenue (Moody, 2004). Moreover, reporting high completion rates is often critical for institutions to secure funding (Patterson \& McFadden, 2009). From the student perspective, course dropout can impede progress towards a degree, cause financial loss, and incur potential psychological distress related to withdrawal decisions (Reed, 1981).

Because of the high costs of student attrition and its association with program quality, there is a critical need for higher learning institutions to be able to predict the potential persistence of online students in order to direct targeted support towards ameliorating the problem (Hachey, Wladis \& Conway, 2013; Parker, 2003). So far, most research on student retention in the online environment focuses on student characteristics (Layne, Boston \& Ice, 2013; for reviews see Levy, 2007; Yukselturk \& Bulut, 2007); little knowledge exists on the impact of course type, even though it has been suggested as a potential online retention risk factor (Diaz, 2002). If course type is an online retention risk factor, then targeting particular courses for intervention, instead of seeking out individual students with particular characteristics, may be a more efficient and reliable way of allocating institutional resources to improve student persistence and online retention rates. We contend that the ability to predict online retention rates based on course characteristics may be extremely useful to institutions, since it could allow them to target with extra resources those particular course sections at highest risk of high online dropout-for example, including dedicated course-type specific counseling and coaching, providing course-specific online readiness surveys or special course orientations, and providing course-specific peer tutors. This study seeks to address the need for information about how course-level characteristics may impact online course retention by identifying and exploring two key factors: the student's reason for taking the course (as an elective or to fulfill a distributional or major requirement); and course difficulty level.

\section{Background}

While several studies have found no significant difference between student learning online versus in traditional face-to-face classrooms (Bernard, et al., 2004; Russell, 2001), research nevertheless indicates a pervasiveness of non-completion in online learning. The online education literature consistently cites lower retention for online courses in comparison to face-to-face courses across higher education in the United States (Angelino, Williams \& Natvig, 2007; Morris \& Finnegan, 2008-9; TylerSmith, 2006) - retention in online learning programs is often reported as 7-20 percentage points lower than traditional campus-based programs (Hachey, Wladis \& Conway, 2013; Moody, 2004; Nora \& Plazas-Snyder, 2008; Patterson \& McFadden, 2009; Smith \& Ferguson, 2005). Based on extensive past findings, we expect to find retention rates to be lower for online courses in comparison to face-to-face courses. Although research has been conducted and findings reported of differences in student retention in online courses across fields (Finnegan, Morris \& Lee, 2008-9; Neil, 2001), there seems to be little evidence in the online education literature looking at the impact of course level or a student's reason for enrolling in the course (to fulfill elective, distributional or major requirements). Thus, what is not clear in the literature is if the risk of dropping out in the online modality is increased based on the type of online course that is taken.

Many studies have considered how student characteristics affect course outcomes. However, this study takes a different approach-it focuses on differences at the course level. Colleges administering online programs are often looking for ways to target interventions at students who are at the greatest risk of poor online performance as compared to face-to-face performance. One way of targeting those students is to use student characteristics; however, this method is time consuming and difficult because it requires colleges to collect and track information on a number of student characteristics which are not routinely collected (e.g. motivation, work hours), and because it requires colleges to target students individually. This study seeks to explore if there are particular courses which may have lower successful online completion rates than would be expected given successful face-to-face completion rates of the same course (taught by the same instructor). If such courses can be identified, then colleges can target 
interventions to those courses at greatest risk, and in this way, target the students at greatest risk. The reason why these courses are at a greater risk online could be a number of things: it could be that the characteristics of students who take these courses make them particularly at-risk in the online environment, or it could be that there are characteristics of the courses themselves that make them more poorly suited to the online environment. The aim of this study is to identify which courses are at risk so that resources could be targeted to these classes; the goal of future work would, thus, be to explore the reasons behind any differences which are uncovered by this study.

\section{Course Difficulty Level}

In this paper, we define course difficulty as the level of a course, or whether a course requires credit-bearing prerequisites. For the college in this study, lower level courses are 100-level courses which do not have prerequisites (other than possible developmental coursework); in contrast, 200-level courses and above require at least one 100-level course as a prerequisite. In this way, 200-level courses cover more advanced material, which is why we refer to them as having a higher difficulty level. There are, of course, other ways in which the difficulty level of a course could be interpreted, but we do not purport to cover all of those interpretations here. Our goal is simply to distinguish between courses which have credit-bearing pre-requisites versus those that do not. Our reasons for focusing on this particular distinction are based on some evidence in the literature that students in lower-level courses may be more vulnerable to doing worse online than would be expected given their face-to-face performance.

Two recent studies of community college students found that students who took online classes early in their college careers were more likely to drop out than those who took only face-to-face courses (Jaggars \& Xu, 2010; Xu \& Jaggars, 2011), which might suggest that students enrolled in lower level classes which are typically taken earlier in a college career might be at greater risk of dropping out. Since difficulty of instructional materials has been cited as one potential reason students drop out of online courses (Diaz, 2002), the level of difficulty of a course may be one factor that may make it more prone to higher attrition in the online environment. Some prior research has found a strong negative correlation between previous education in the discipline and dropping out of an online course. This indicates that students may be more likely to drop out of lower level online courses, particularly when they are in a subject unrelated to their prior course experience. In other words, students may be more likely to drop lower level online courses that are outside their major (Xenos, Pierrakeas \& Pintelas, 2002).

\section{Reason for Course Enrollment (to fulfill Elective, Distributional or Major Requirements)}

In particular, there seems to be little research that looks at whether the decision to enroll in required versus elective online courses has an impact on online retention. Student perceptions of online learning have been shown to be a better predictor of outcomes at the post-secondary level than grade point average (G.P.A.) (Lizzio, Wilson \& Simons, 2002; Sutton \& Nora, 2008). Moreover, across most disciplines, whether a course is an elective or a requirement is a variable that has been linked to student attitudes (Babad, 2001). Consistently in the face-to-face course literature, elective courses receive better evaluations than required courses (for a review, see Darby, 2006). Given the influence of student perception on persistence, this suggests that retention for elective courses may be higher than required courses. However, Reed (1981) contends that persistence in a course is significantly related specifically to students' belief in the relevance of the course to their need and, further, found that students were much more likely to drop courses that were electives.

Rational choice theory may provide an additional framework, beyond that of student persistence, for examining student course selection. Rational choice theory posits that individuals will base their activities and decisions on a cost-benefit analysis (Coleman \& Fararo, 1992). If students believe there is a greater "pay off" from a specific course or set of courses, it may induce the student to persist. Students might consider there to be a greater "payoff" when selecting and completing courses that are required for their degree versus electives, and may therefore be more likely to persist in required courses. Additionally, to the extent that students perceive courses in the online environment to be less rigorous, this perception might be an inducement for enrollment. However, such perceptions may also lead to 
greater attrition when students find the course to be more difficult than originally thought (Moody, 2004). Course workload and course difficulty are oft cited reasons for course withdrawal but often not the primary reason (Babad, Icekson \& Yelenik, 2008; Summer \& Johnson Community College, 2001). In a survey of 500 undergraduates enrolled in face to face courses, Babad \& Tayeb (as cited in Babad, Icekson \& Yelinek, 2008) found that students primarily dropped a course due to "atmosphere', a factor that was a composite of both a student's connection with classmates (the number of students, the quality of the discussion) and physical conditions (classroom crowding and the characteristics of the room itself). But as Babad \& Tayeb (as cited in Babad, Icekson \& Yelinek, 2008) assert, the components of "atmosphere" used in this study may be more nebulous in the online environment.

At the college in this study, an interesting pattern was observed during a preliminary review of retention rates that seemed to suggest that the online environment may affect the retention rate more strongly for students taking courses as a distributional versus a major requirement. Retention rates in two different mathematics courses taught by the same professor, in the same semester, and with the same prerequisites were significantly different for the online section of the course as compared to the face-toface section. Fundamentals of Mathematics (MAT 100) is taken by liberal arts majors as one option for fulfilling their mathematics distributional requirement. Mathematics for Health Sciences (MAT 104) is a required course in certain health care majors such as paramedics and nursing, with the course content entirely focused on applied problems in the field. In this example, the attrition rate in the online section of MAT 100 (the distribution requirement) was almost double that of its face-to-face counterpart; whereas the attrition rate in MAT 104 (the major requirement) was slightly (but not significantly) lower in the online environment compared to the face-to-face version. These preliminary findings suggest that an exploration of course-level factors, such as a student's reason for taking a course (to fulfill elective, distributional, or major requirements), is a logical next step in building predictive models of online student persistence. If course-level factors can be identified which allow institutions to identify courses which are at risk of significantly higher attrition rates in the online environment than would be expected given attrition rates in face-to-face environments, then interventions can be targeted to these courses. The reason why some courses may be at a greater risk in their online form could be that the characteristics of students who take these courses make them particularly at-risk in the online environment; however, focusing interventions on students with specific characteristics is more resource-intensive and difficult

than targeting particular types of courses. Therefore, this study focuses on characteristics which are at the course rather than student level.

\section{Purpose of the Study}

The purpose of this study is to assess the extent to which students' reasons for taking a course (to fulfill elective, distributional, or major requirements) and course difficulty level may be used as predictors of online versus face-to-face course outcomes. Therefore, the following questions are addressed:

Which combinations of course-level factors (elective vs. distributional vs. major requirements; level) have retention rates that are significantly lower online than face-to-face?

When comparing online and face-to-face sections of the same course, is the gap in retention rates larger for courses which students take as elective or distributional requirements than for courses which students take to fulfill major requirements?

When comparing online and face-to-face sections of the same course, is the gap in retention rates larger for lower-level (100-level) courses than for upper-level (200-level and above) courses?

Is there an interaction between a student's reason for taking a course (to fulfill elective, distributional or major requirements) and course difficulty level in predicting online versus face-to-face course retention? For example, is the correlation between a student's reason for taking a course and online course outcomes greater for lower-level courses than for upper-level courses? 
The Role of Enrollment Choice in Online Education

\section{Methodology}

\section{Data Source and Sample}

This study utilizes data provided by the Office of Institutional Research from a large, urban community college in the Northeast region of the United States. Enrolling approximately 23,500 students in degree-programs each year, the college meets the requirements to be deemed a "large institution", according to Allen \& Seaman (2010). This is noteworthy as large institutions educate nearly two-thirds (64\%) of all online students. The gathered data represents a diverse student body, as enrollees come from over 150 countries around the world. Eighty percent of the College's student population belongs to groups historically underrepresented in higher education: the College is classified as both a Minority Serving Institution and a Hispanic Serving Institution. The College has offered online classes since 2002, and currently offers a fully online Associate's Degree in Liberal Arts in addition to over 135 online courses.

Data was compiled for 122 course sections (half taught online and half taught face-to-face). The course sections to be included in the sample were selected from a larger pool using the following methods: first, data were obtained for all online course sections taught from 2004-2010 (fall and spring semesters). Second, the sample was limited to include only those course sections for which an instructor taught the same course both face-to-face and online in the same semester, to control for instructor effects. Next, the sample was reduced to only those courses which the instructor had taught for at least three semesters, to limit the effects of instructor inexperience in the online environment. In total, 21 different courses taught by 23 different instructors both online and face-to-face were included. The courses were well distributed across disciplines, with three in business, one in nursing, five in the humanities, five in the social sciences, four in mathematics, and three in science disciplines.

\section{Measures}

For each section in the sample, student data was provided stripped of personal identifiers; unique identification numbers were used to distinguish participants. This resulted in a total dataset of 2,330 participants. The following information was obtained for every student: student major (used to determine if the course was taken as a requirement or elective) and final grade in the course (including withdrawal status). The categorization of a course as an elective, distributional requirement, or major requirement for each student was determined based on the requirements of students' majors: courses which did not fulfill any particular curriculum requirement (other than general elective credits) were counted as electives; courses that fulfilled a degree requirement not part of the major's core curriculum were counted as distributional requirements; and courses that were either explicitly required as a part of a major's core curriculum, or were elective major courses that counted as major requirements for a particular student were coded as major requirements. Major requirements were not always limited to courses in the exact subject of the student's major. Courses in related fields were also counted as major requirements if they were listed by a department as being required for the major in the college catalog.

The dependent variable which was the focus of this study was retention: students were categorized as having completed the course if they were still attending class after the tenth week of the semester (only fall and spring semesters were included in the analysis). Students who never attended the course or who received an incomplete grade were excluded from the analysis.

\section{Data Analyses}

First we performed significance tests using the Bonferroni procedure and $z$-scores to determine whether different types of courses in the sample had significantly different retention rates (online versus face-to-face; lower-level versus upper-level; elective versus distribution versus major requirements). Then we used these same types of significance tests to determine whether each course subtype (lower level; upper level; elective; distributional requirement; major requirement) had significantly lower retention rates in their online form versus their face-to-face form. Based on current research literature, we expected (but did not assume) average retention rates to be lower online than in face-to-face sections. 
However, because the existence, direction, and size of the gap between online and face-to-face completion rates may vary by course type, we used binary logistic regression to determine if any differences in the size or direction of retention rate gaps between different course types (elective, distributional, major requirement) were significant by interacting course-level characteristics with the course medium (online versus face-to-face).

We performed significance tests using the Bonferroni procedure and $z$-scores to determine whether online and face-to-face retention rates were significantly different for combinations of subtypes of courses (e.g. lower level electives). We then conducted separate binary logistic regression models for lower level courses and for upper level courses that compared the differences in size and direction for the gap between online and face-to-face courses among elective versus distributional versus major requirements.

\section{Preliminary Analysis of the Data}

\section{Results and Discussion}

As a precursor to analyzing differences in retention in different online course types, we first analyzed whether, in this sample, there were generally (not just online) differences in attrition rates among courses taken to fulfill elective versus distributional versus major requirements, or among upper versus lower level courses. Pooling all students in the sample in both online and face-to-face courses to compute retention rates for each category yields the data in Table 1, which includes tests for significance. (We note that Retention rates and Attrition rates are complements of one another: the Attrition rate is the percentage of students who withdrew from the course officially or unofficially [i.e. a student stopped attending class sometime before the tenth week of the semester-students who stop attending after the 10 th week of classes receive an "F" grade instead], whereas the Retention rate is the percentage of students who did not withdraw officially or unofficially, but may have earned an "F" or "D" grade.)

Table 1 Retention rates for students in each classification of course type, with tests for significance.

\begin{tabular}{lrrrrr}
\hline & retention & $\boldsymbol{n}$ & \multicolumn{1}{c}{$\mathbf{z}$} & $\boldsymbol{p}$ & z-score compares: \\
\hline face-to-face & $81.0 \%$ & 1107 & 5.46 & $<\mathbf{0 . 0 0 0 1}$ & face-to-face vs. online \\
online & $70.6 \%$ & 887 & & & \\
lower level & $69.3 \%$ & 1092 & -8.16 & $<\mathbf{0 . 0 0 0 1}$ & lower level vs. upper level \\
upper level & $84.9 \%$ & 902 & & & \\
elective & $67.7 \%$ & 449 & -2.79 & $n s$ & elective vs. dist. req. \\
dist. req. & $74.8 \%$ & 980 & -5.21 & $<\mathbf{0 . 0 0 0 1}$ & dist. req. vs. major req. \\
major req. & $86.0 \%$ & 565 & 6.98 & $<\mathbf{0 . 0 0 0 1}$ & elective vs. major req. \\
\hline
\end{tabular}

Results for $p$-values in bold are all highly statistically significant ( $\alpha=0.01$, two-tailed), even when the Bonferroni procedure is used to control for Type I error. The abbreviation ns means that the result is not statistically significant.

In Table 1 it is apparent that attrition is higher: 1) in online courses compared to face-to-face courses; 2) in lower level courses compared to upper level courses; and 3) in courses that are elective or distributional requirements rather than major requirements. All of these differences are highly statistically significant $(\alpha=0.01)$.

\section{Differences in online versus face-to-face course retention rates for different combinations of course- level factors}

Next, we considered the interaction between the method of course delivery (online vs. face-toface) with course type (elective vs. distributional requirement vs. major requirement) and level. Retention rates for each course-level factor can be seen in Table 2 broken down by course delivery modality. 
Table 2 Retention rates online and face-to-face for different course types, with tests for significance

\begin{tabular}{lcccccr}
\hline & $\begin{array}{c}\text { face-to-face } \\
\text { retention }\end{array}$ & $\boldsymbol{n}$ & $\begin{array}{c}\text { online } \\
\text { retention }\end{array}$ & $\boldsymbol{n}$ & $\boldsymbol{Z}$ & \multicolumn{1}{c}{$\boldsymbol{p}$} \\
\hline lower level & $75.5 \%$ & 593 & $61.9 \%$ & 499 & $4.86^{* *}$ & $<0.0001$ \\
upper level & $87.4 \%$ & 514 & $81.7 \%$ & 388 & 2.35 & $n s$ \\
elective & $77.8 \%$ & 203 & $59.3 \%$ & 246 & $4.17^{* *}$ & $<0.0001$ \\
dist. req. & $79.1 \%$ & 560 & $69.0 \%$ & 420 & $3.59 * *$ & $<0.0001$ \\
major req. & $86.0 \%$ & 344 & $86.0 \%$ & 221 & 0.02 & $n s$ \\
\hline ** indicates significance level of $\alpha=0.01$ (one-tailed) for overall set of tests \\
(adjusted to 0.0011 per test using the Bonferroni procedure)
\end{tabular}

In Table 2, retention followed the same pattern in the online environment as in the face to face environment: retention was greater in upper level and major requirement courses versus lower level and elective or distributional requirement courses. Additionally, the following course types had a highly statistically significantly $(\alpha=0.01)$ lower retention rate online than face-to-face: lower level courses; elective courses, and courses that fulfill distributional requirements. This suggests that whatever factors lead to lower overall retention rates for lower level, elective, and distributional requirement courses (e.g. lower levels of student motivation) may be amplified by the online environment. The differences in online versus face-to-face course outcomes by course type are illustrated graphically in Figure 1.

Figure 1 Online and Face-to-Face Retention for Electives vs. Distributional Requirements vs. Major Requirements

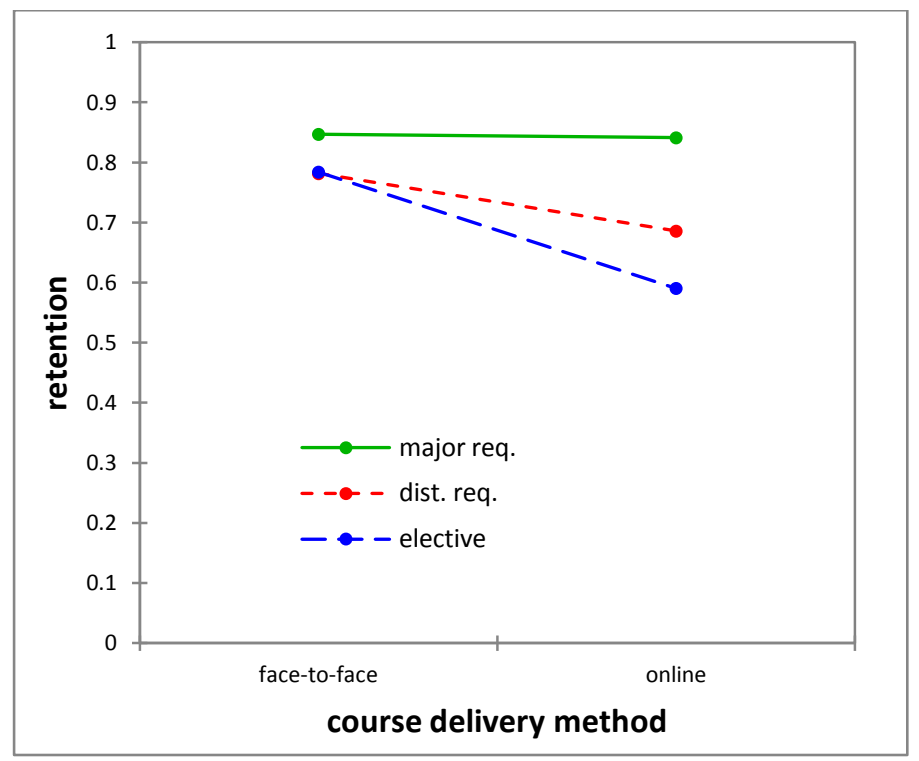

It is evident from Figure 1 that students who take an online course which fulfills their major requirements are roughly equally as likely to remain in the course whether they take it online or face-toface, while students who take the course to fulfill a distributional requirement or as an elective are much more likely to withdraw online than in the face-to-face environment, with this difference particularly pronounced for electives. To determine if the slopes of the lines in Figure 1 are statistically significant, we performed a binary logistic regression with retention as the dependent variable and course delivery method and course type as the independent variables. We also included the interaction between these two factors as a term in the regression equation. The results of this analysis can be seen in Table 3. 
The Role of Enrollment Choice in Online Education

\begin{tabular}{lcc}
\hline Table 3 Type III analysis for binary logistic regression analysis of the interaction effect of course delivery method and \\
course type on retention
\end{tabular}

When the interaction between course delivery method and course type is taken into account, the interaction between course type and course delivery method is statistically significant $(\alpha=0.05)$. In other words, the differences in slope that we see in the lines in Figure 1 are statistically significant, and students in elective and distributional requirement courses have a much higher jump in attrition when they move to the online environment than students in major requirement courses.

But what happens if course type and level are combined? For example, would an upper level elective course have lower online retention or not? To address these questions, we next analyzed differences in retention rates for the two factors of course type and level, both online and face-to-face.

\section{How does course level interact with course type and the online environment in predicting course outcomes?}

First we looked at each subgroup of course level by type (e.g. lower level elective courses, upper level distributional requirements, etc.), to see which of these groups had retention rates that were lower in the online environment. This data is displayed in Table 4.

Table 4 Retention rates online and face-to-face for different combinations of course type, with tests for

\begin{tabular}{lllrrrrr}
\hline \multicolumn{7}{c}{ significance } \\
\hline level & type & $\begin{array}{l}\text { face-to-face } \\
\text { retention }\end{array}$ & $\boldsymbol{n}$ & $\begin{array}{c}\text { online } \\
\text { retention }\end{array}$ & $\boldsymbol{n}$ & $\boldsymbol{z}$ & $\boldsymbol{p}$ \\
\hline lower level & elective & $74.30 \%$ & 105 & $52.10 \%$ & 165 & 3.64 & $<0.0001^{* *}$ \\
lower level & dist. req. & $75.90 \%$ & 390 & $64.50 \%$ & 290 & 3.24 & $0.0006^{* *}$ \\
lower level & major req. & $75.50 \%$ & 98 & $81.80 \%$ & 44 & -0.83 & $n s$ \\
upper level & elective & $81.60 \%$ & 98 & $74.10 \%$ & 81 & 1.21 & $n s$ \\
upper level & dist. req. & $86.50 \%$ & 170 & $79.20 \%$ & 130 & 1.68 & $n s$ \\
upper level & major req. & $90.20 \%$ & 246 & $87.00 \%$ & 177 & 1.03 & $n s$ \\
\hline * indicates a significance level of $\alpha=0.01$ (one-tailed) for overall set of tests (adjusted to 0.0017 \\
per test using the Bonferroni procedure)
\end{tabular}

In Table 4, it is apparent that lower level courses taken as either electives or to fulfill distributional requirements have statistically significantly $(\alpha=0.01)$ lower retention rates online than faceto-face, whereas this effect is not seen for major requirements or for upper level courses. In Figure 2 and Figure 3, these differences are displayed graphically.

For lower level courses (Figure 2), all course designation types (electives, distributional requirements and major requirements) have almost identical retention rates face-to-face. In the online environment, however, these retention rates greatly diverge, covering a range that is about thirty percentage points wide. For lower level courses in the online environment, major requirement courses have retention rates that are actually a bit higher than in the face-to-face environment (although this difference is not statistically significant), whereas distributional requirement courses have retention rates that are significantly lower online, and elective courses have retention rates that are much significantly lower online. In contrast, for upper level courses, major requirement courses have higher retention than distributional requirement courses, which have higher retention than elective courses, but this pattern is 
nearly identical both online and face-to-face: the gap between courses is about the same both face-to-face and online, and the retention rates for each category, while slightly lower online, are not statistically different from the retention rates for each corresponding category face-to-face.

Figure 2 Retention for Lower Level (LL) courses by type and delivery method

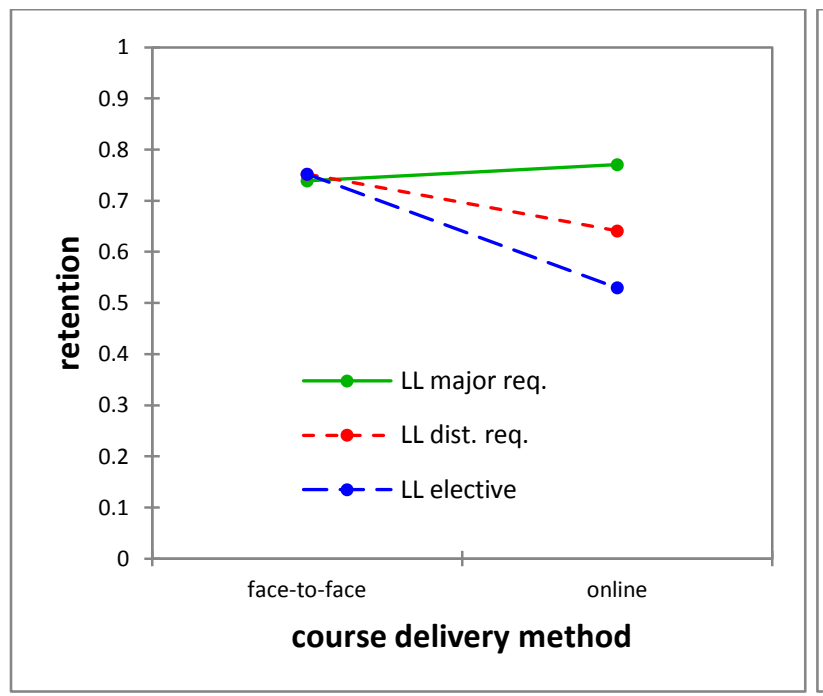

Figure 3 Retention for Upper Level (UL) courses by type and delivery method

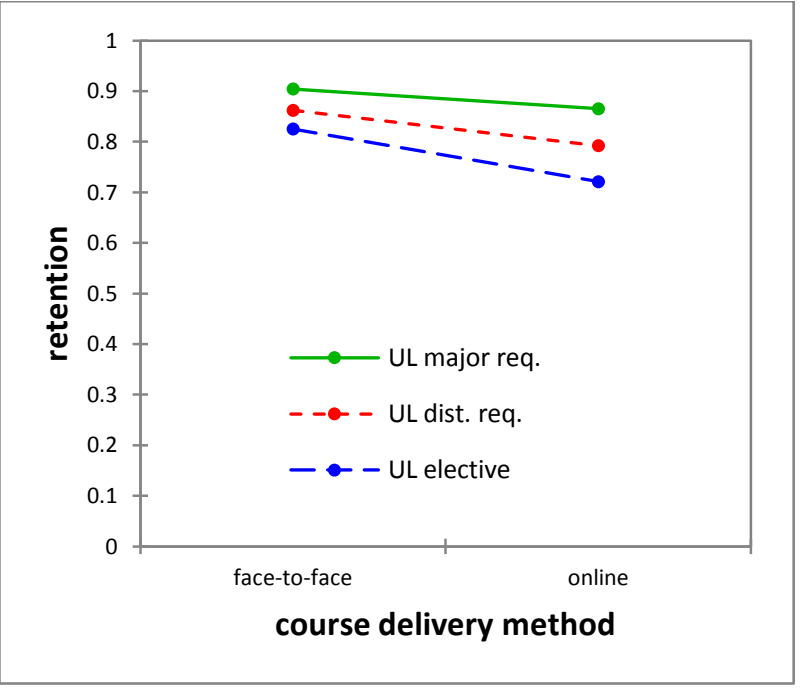

To determine whether or not the differences in slopes in Figure 2 and Figure 3 are statistically significant, we performed a binary logistic regression - first on lower level courses only, and then on upper level courses only - to determine what effect the interaction of course delivery method and course type might have on retention. These results can be seen in Table 5.

\begin{tabular}{|c|c|c|}
\hline lower level courses & Chi-square (LR) & $\operatorname{Pr}>$ LR \\
\hline course delivery method & 0.226 & 0.634 \\
\hline course type & 0.096 & 0.953 \\
\hline course delivery method* course type & 7.356 & $0.025 *$ \\
\hline-2 Log Likelihood & 1556.1 & \\
\hline $\mathrm{R}^{2}$ (Nagelkerke) & 0.042 & \\
\hline upper level courses & Chi-square (LR) & $\operatorname{Pr}>$ LR \\
\hline course delivery method & 6.889 & $0.009 * *$ \\
\hline course type & 12.385 & $0.002 * *$ \\
\hline-2 Log(Likelihood) & 769.0 & \\
\hline $\mathrm{R}^{2}$ (Nagelkerke) & 0.037 & \\
\hline
\end{tabular}

In Table 5, we can see that once the interaction between course delivery method and course type is taken into account in the lower level course subsample, the interaction is statistically significant. So the differences in slope that are visible in Figure 2 are in fact statistically significant, and knowing the type or delivery modality of a course alone does not provide us particularly useful information for predicting online course outcomes in lower level courses. Instead the differences in retention rates among these different categories is better captured by knowing the course type and modality subcategory (for example, knowing that a course is online, or is an elective is not enough to predict a retention rate that might be different from average for lower level courses, but knowing that a course is an elective online is 
predictive of retention).

Table 5 also gives the results of a binary logistic regression analysis on upper level courses. In this model the interaction term was omitted because it was not significant, and both course modality and type are significant predictors of retention, which is what we would expect from looking at the graph. For upper level courses, online retention rates are slightly but significantly lower, and the retention rates for major requirements are higher than for distributional requirements, which are in turn higher than for electives, in both the online and face-to-face modality. Planned pairwise comparisons during the binary logistic regression analysis (not shown here for the sake of brevity) show that distributional requirements and electives had statistically lower retention rates overall, but that the difference between elective and distributional requirements was not significant. This means that for upper level courses, unlike for lower level courses, the effects of the online environment on retention seem to be roughly the same across all course types.

\section{Limitations}

This research was limited to a specific sample chosen from a single community college, and as such, these results may not necessarily generalize nationally or to four-year institutions. However, this limitation is mitigated in several important ways. First, the community college in this study has a very diverse student body. Second, because the study focuses on a large urban community college, the sample the data was drawn from is representative of the types of institutions which educate the vast majority of community college students in the United States, since $82 \%$ of all community college students attend institutions in or on the fringe of mid- and large-sized cities (U.S. Department of Education, Institute of Education Sciences, National Center for Education Statistics, 2003). This suggests that research based on the college in this study may be relevant to a large proportion of community college students nationally. Finally, studying students within a single institution rather than across institutions limits threats to internal validity, because faculty conditions, course requirements and institutional elements are more uniform within a single institution (Nora \& Cabrera, 1996).

In addition, controlling courses by instructor and semester (including in the sample only pairs of course sections taught by the same instructor both online and face-to-face in the same semester) limits the total number of possible instructors included in the sample, and therefore each instructor may have greater influence on the results. Because all the instructors in this sample taught online for at least three semesters (many of them much longer) and because the college in this study does not let faculty continue to teach a course online if students in their courses have very low retention rates, it is unlikely that a small number of faculty with particularly low retention rates strongly affected the results. With that said, it would be necessary to repeat this study with larger sample sizes at other institutions to confirm the general trends observed here.

Additionally, the differences in significance for factors in the models included in Table 5 for lower level courses versus upper level courses is not in and of itself proof of a three-way interaction between course type, level, and delivery method. Technically only a larger binary logistic regression model containing all two-way and three-way interactions could ascertain the statistical significance of the differences between the trends seen in Figure 2 for lower level courses versus those seen in Figure 3 for upper level classes. However, the sample size in this particular study was not sufficiently large to allow for the necessary statistical power to perform such a test. As such, the differences observed between the patterns seen in Figure 2 and Figure 3 should be interpreted as preliminary results only, which should be tested with larger samples. From the institutional perspective, the results of such a statistical test may be less relevant: to improve online retention rates, it may not be necessary to determine for certain whether the patterns observed for upper level courses in Figure 3 are truly significantly different from those observed for lower level courses in Figure 2. Rather, the simple fact that lower level courses taken as electives or distributional requirements have the highest drop in retention when moved to the online environment suggests that targeting this specific subgroup of courses for extra support in the online environment may be sufficient to improve overall online attrition. 
Lastly, this research did not explore differences in student characteristics. Numerous studies, including our own (e.g. Jaggars \& Xu, 2010; Wladis, Hachey, \& Conway, in press; Xu \& Jaggars, 2011), have shown that students who possess certain non-traditional characteristics, including being older, working, attending part-time and supporting dependents, are more likely to enroll in online courses. These same characteristics are also factors which have been shown to negatively impact persistence, regardless of course modality. However, the goal of this research is not to compare outcomes of online versus face-to-face students directly. Rather, the goal of this study is to look at the interaction between the online medium and course characteristics, which focuses instead on exploring when the gap between online and face-to-face completion rates is significantly larger or smaller for different types of courses.

It is possible that certain types of courses attract students who are more likely to be at risk in online environments, and this could explain any significant differences in the online-versus-face-to-face course completion gap for specific course types. Our study does not discount this as a possible reason for differences in outcomes for different types of courses. For example, students who are enrolled in more advanced level courses have already succeeded to an extent that has not (and may not) occur for students enrolled in lower level courses, and this may explain the differences in the online-versus-face-to-face course completion gap for higher versus lower level courses. Whatever the reason for larger gaps in specific types of courses, identifying courses with larger gaps could allow institutions to target interventions specifically to those course types. Identifying courses that are at highest risk in the online environment allows resources to be targeted to these classes, and then the goal of future work would be to explore the reasons behind differences which have been uncovered by this study.

\section{For Practice}

\section{Implications}

Ludwig-Hardman \& Dunlap (2003) contend that individualization in learner support services is greatly needed to increase retention in online courses. This research suggests that online course retention rates can be improved by providing extra support targeted specifically to lower level courses which are typically taken as electives or to satisfy distributional requirements. Such support could include selfassessment and orientation tools which could be used to help students assess their perceptions and preparedness for the course. At the course level, E-advisors could provide an early mechanism for academic counseling, additional technical support staff could assist students with technical difficulties specific to the online environment, and peer tutors could assist students with the course content. Such measures could improve retention rates for these courses where students are at highest risk of dropping out. Retention online overall could be improved just by targeting the subgroups of courses at highest risk (thereby more efficiently allocating resources). In particular, for the sample in this study, if an intervention (effective enough to improve retention online to the level typical in comparable face-to-face courses) was targeted only at lower level elective and distributional requirement courses, the overall online persistence rate would have jumped from $70.6 \%$ to $78.4 \%$, and this increase in overall online course persistence would be sufficient to close the gap with overall face-to-face persistence rates (80.0\%). The $78.4 \%$ online persistence rate that could be obtained by such an intervention is not significantly different from the $80.0 \%$ face-to-face persistence rate (at the $\alpha=0.05$ level with a one-tailed $z$-test). This suggests that if a sufficiently effective intervention could be implemented, any online and face-to-face attrition rate gap could be closed by targeting just roughly half of the online courses offered at this college.

Some institutions might conclude from these results that they should limit or prohibit certain types of courses to be taught online, because those courses have a lower retention rate online than face-toface. While this might raise average online retention rates, in practice it would be impractical by limiting access for a huge number of students, and would be a misapplication of the conclusions in this analysis. It is important to note that the designation as an elective or distributional requirement lies with the student, not the course, as it depends upon a student's major. For example, English 201 may be taken at 
the college in this study by many students as a distributional requirement, but for English or Writing majors, this course actually fulfills their major requirements. Even if it were practical, removing all the students from online courses who took the course as an elective or a distributional requirement would require prohibiting more than half of the online students from taking courses online, which would defeat the purpose of online education in providing greater access to higher education. In particular, the many students who do succeed in these online courses would have fewer course options and, therefore, might be less likely to persist in college and complete college degrees. Furthermore, removing certain types of courses from the online environment may not actually improve overall online retention. For example, it may be that lower level online courses have lower retention because they contain a much higher proportion of students taking an online course for the first time. If this is the case, eliminating lower level online courses may then simply shift increased drop-out rates from lower level to upper level courses.

\section{For Research}

This study has shown that the type of course in which students enroll can have a drastic effect on their likelihood of withdrawal from online courses. However, before larger generalizations can be made about which types of courses lead to lower retention online in the general college student population, this analysis should be repeated with diverse samples across different campuses. In addition, the reasons for the lower rates of retention in lower level online classes taken as electives and distributional requirements are unclear, and further research could help to explain the reasons for these results.

\section{Acknowledgements}

Support for this project was provided by PSC-CUNY Award number 64715-00 42, The Professional Staff Congress and The City University of New York, and by a BMCC/CUNY Title V Faculty Research Stipend, funded by the U.S. Dept. of Education.

\section{References}

Abel, R. (2005). Achieving success in Internet support learning in higher education: Case studies illuminate success factors, challenges and future directions. Alliance for Higher Education Competitiveness. Retrieved on August 21, 2011 from http://www.a-hec.org/media/files/AHEC_IsL0205_6.pdf

Allen, I.E. \& Seaman, J. (2010). Class Differences: Online Education in the United States, 2010. Sloan Foundation Publication. Retrieved on June 4, 2010 from http://sloanconsortium.org/publications/survey/pdf/class_differences.pdf.

Allen, I., \& Seaman, J. (2013). Changing course: Ten years of tracking online education in the United States. Retrieved June 20, 2013, from http://www.onlinelearningsurvey.com/reports/changingcourse.pdf.

Angelino, L.M., Williams, F.K. \& Natvig, N. (2007). Strategies to engage online students and reduce attrition rates. The Journal of Educators Online, 4(2).

Babad, E. (2001). Students' course selection: Differential considerations for first and last course. Research in Higher Education, 42(4), 469-492.

Babad, E., Icekson, T., \& Yelinek, Y. (2008). Antecedents and correlates of course cancellation in a university "Drop and Add" period. Research in Higher Education, 49(4), 293-316.

Bernard R.M., Abrami P.C., Lou Y., Borokhovski, E., Wade A., Wozney L., ... \& Huang, B. (2004). How does distance education compare to classroom instruction? A meta-analysis of the empirical literature. Review of Educational Research, 74(3), 379-439.

Boston, W.E. \& Ice, P. (2011). Assessing retention in online learning: An administrative perspective. Online Journal of Distance Learning Administration, 14(2). 
Coleman, J. S. \& Fararo, T. J. (1992) Rational choice theory: Advocacy and critique, Newbury Park, CA: Sage.

Community College Research Center (CCRC). (2013). Research Overview/April 2013: What we know about online course outcomes. Retrieved August 1, 2013 from http://ccrc.tc.columbia.edu/publications/what-we-know-online-course-outcomes.html

Darby, J.A. (2006). The effects of the elective or required status of a course on student evaluations. Journal of Vocational Education and Training, 58(1), 19-29.

Diaz, D.P. (2002). Online drop rates revisited. The Technology Source, May/June. Retrieved on September 7, 2009 from http://technologysource.org/article/online_drop_rates_revisited/

Finnegan, C., Morris, L.V. \& Lee, J. (2008-9). Difference by course discipline on student behavior, persistence, and achievement in online courses of undergraduate general education. Journal of College Student Retention: Research, Theory \& Practice, 10(1), 39-54.

Hachey, A.C., Wladis, C.W. \& Conway, K.M. (2013). Balancing retention and access in online courses: Restricting enrollment... Is it worth the cost? Journal of College Student Retention: Research, Theory \& Practice, 15(1), 9-36.

Howell, S., Williams, P., \& Lindsay, S. (2003). Thirty-two trends affecting distance education: An informed foundation for strategic planning. Online Journal of Distance Learning Administration, 6(3).

Jaggars, S.S. \& Xu, D. (2010). Online learning in the Virginia Community College System. New York: Community College Research Center, Teachers College, Columbia University. Retrieved on June 4, 2011 from http://ccrc.tc.columbia.edu/Publication.asp?uid=813

Layne, M., Boston, W., \& Ice, P. (2013). A longitudinal study of online learners: Shoppers, swirlers, stoppers, and succeeders as a function of demographic characteristics. Online Journal of Distance Learning Administration, 16(2).

Larreadmendy-Joerns, J. \& Leinhardt, G. (2006). Going the distance with online education. Review of Educational Research, 76(4), 567-605.

Levy, Y. (2007). Comparing dropouts and persistence in e-learning courses. Computers and Education, 48, 185-204.

Lizzio, A., Wilson, K., \& Simons, R. (2002). University students' perceptions of the learning environment and academic outcomes: Implications for theory and practice. Studies in Higher Education, 27(1), 27-52.

Ludwig-Hardman, S. \& Dunlap, J.C. (2003). Learner support services for online students: Scaffolding for success. The International Review of Research in Open and Distance Learning. Retrieved on June 5, 2011 from http://www.irrodl.org/index.php/irrodl/article/viewArticle/131/211

Moody, J. (2004). Distance education: Why are the attrition rates so high? The Quarterly Review of Distance Education, 5(3), 205-210.

Morris, L.V. \& Finnegan, C.L. (2008-9). Best practices in predicting and encouraging student persistence and achievement online. Journal of College Student Retention: Research, Theory \& Practice, vol. 10(1), 55-64.

Neil, T. (2001). Assessing enrollment and attrition rates for the online MBA. T.H.E. Journal, 28(7), 6470.

Nora, A., \& Cabrera, A. (1996). The role of perceptions of prejudice and discrimination on the adjustment of minority students to college. The Journal of Higher Education, 67(2), 119-148. 
The Role of Enrollment Choice in Online Education

Nora, A. \& Plazas Snyder, B. (2008). Technology and higher education: The impact of E-learning approaches on student academic achievement, perceptions and persistence. Journal of College Student Retention: Research, Theory \& Practice, 10(1), 3-19.

Parker, A. (2003). Identifying predictors of academic persistence in distance education. United States Distance Learning Association (USDLA) Journal, 17(1).

Patterson, B. \& McFadden, C. (2009). Attrition in online and campus degree programs. Online Journal of Distance Learning Administration, 12(2).

Pearson Foundation. (2011). Community College Student Survey: Summary of Results. Pearson Foundation. $\quad$ Retrieved $\quad$ February $1, \quad 2012$ from http://www/pearsonfoundation.org/downloads/Community_College_Survey_Summary_201102.p df.

Reed, J.G. (1981). Dropping a college course: Factors influencing students' withdrawal decisions. Journal of Educational Psychology, 7(33), 376-385.

Russell, T. (2001). The no significant difference phenomenon, Raleigh, NC: North Carolina State University.

Smith, G., \& Ferguson, D. (2005). Student attrition in mathematics elearning. Australasian Journal of Educational Technology, 21(3), 323-334.

Summer, P., \& Johnson County Community Coll., O. h. (2001). Drop Study/Attrition Rates, Fall 2000. [serial online]. March 1, 2001; Available from: ERIC, Ipswich, MA.

Sutton, S. \& Nora, A. (2008). An exploration of college persistence for students enrolled in web-enhanced courses: A multivariate analytic approach. Journal of College Student Retention: Research, Theory \& Practice, 10(1), 21-37.

Tyler-Smith, K. (2006). Early attrition among first time E-learners: a review of factors that contribute to dropout, withdrawal and non-completion rates of adult learners undertaking E-learning programs. Journal of Online Learning and Technology, 2(2), 73-85.

U.S. Department of Education, Institute of Education Sciences, National Center for Education Statistics (NCES). (2003). Integrated Postsecondary Education Data System (IPEDS). Washington, D.C.: U.S. Department of Education. Retrieved from http://nces.ed.gov/ipeds/datacenter/.

Willging, P.A. \& Johnson, S.D. (2004). Factors that influence students' decision to drop out of online courses. Journal for Asynchronous Learning Networks, 8(4), 105-118.

Wladis, C. W., Hachey, A. C., \& Conway, K. M. (in press). The representation of minority, female, and non-traditional STEM majors in the online environment at community colleges: A nationally representative study. Community College Review.

Xenos, M., Pierrakeas , C. \& Pintelas, P. (2002). A survey on student dropout rates and dropout causes concerning students in the course of Informatics at Hellenic Open University. Computers and Education, 39, 361-377.

Xu, D. \& Jaggars, S.S. (2011). Online and Hybrid Course Enrollment and Performance in Washington State Community and Technical Colleges (CCRC Working Paper No. 31). New York: Community College Research Center, Teachers College, Columbia University. Retrieved on July 3, 2011 from http://ccrc.tc.columbia.edu/Publication.asp?UID=872

Yukselturk, E. \& Bulut, S. (2007). Predictors for student success in an online course. Educational Technology and Society, 10(2), 71-83. 